\title{
IOT in Agricultural Crop Protection and Power Generation
}

\author{
Anjana $\mathrm{M}^{1}$, Charan Kumar $\mathrm{A}^{2}$, Monisha $\mathrm{R}^{3}$, \\ Sahana R H ${ }^{4}$ \\ 1, 2, 3, 4 Student, \\ Department of Electronics and Instrumentation \\ Engineering, \\ JSS Academy of Technical Education \\ Bangalore, India
}

\author{
Mrs. Sowmya M S \\ Asst. Prof., \\ Department of Electronics and Instrumentation \\ Engineering, \\ JSS Academy of Technical Education \\ Bangalore, India
}

\begin{abstract}
Agriculture is the science and art of growing plants. Agriculture plays predominant position in the financial improvement of our country and this is the primary profession from many years. To extend the efficiency of the yields and to limit the costs of rural practices we go for smart techniques of agriculture by using IOT technology. Protection of crop during rainy season is major challenge for farmers. By incorporating Greenhouse technology, an environment condition for a crop to grown will created along the various features like sensor based totally monitoring, security, crop safety from excessive rain and automatic roof overlaying facility. Greenhouse is operated in two modes i.e, automatic mode and manual mode. It makes use of telegram app for communicating with the cultivators about various environmental factors continuously. Various sensor nodes are deployed at special locations in the greenhouse. Controlling those parameters are through any remote device or internet services and the operations are completed by means of interfacing sensors, with microcontroller. Power generation and supply is usually a massive problem. This project is also consisting of solar power generation and rainwater harvesting as technology method is implemented along with crop safety.
\end{abstract}

Keywords-Greenhouse; agriculture; microcontroller; crop security

\section{INTRODUCTION}

Agriculture is the important sector and backbone of our country. Many of our Indian people depends on agriculture. About 58\% people depends only on agriculture.38\% of GDP of Indian economy contributed by agriculture. It depends on monsoon and rainfall, so it is still under development. Adoption of irrigation and scientific methods helps in improvement of agriculture. Greenhouse, polyhouse kind of improved and protected method helps to yield more. Even agriculture is adopted my many people in India, but production percentage is less. Compare to other countries like USA, China, Germany and Italy our production level is low, and we are importing food grains from them.

If we wanted to earn more profit from agriculture, we must adopt modern farming techniques such as Greenhouse farming (polyhouse farming), hydroponic farming etc. Government is also encouraging these types of modern technologies to increase the yield and provide funds through different schemes. Central government provide subsidy, loan for greenhouse, cent polyhouse, shade net house scheme to encourage modern method of agriculture. The government is continuously making efforts to develop agriculture sector and It is one of the fields where government stress a lot and we have come a long way in agricultural development.

Greenhouse is a structure with walls and roof made up of transparent material, such as glass or translucent material. In green house environment plants are grown in a required regulating climatic condition. These structures may vary in different structures and sizes including small sheds to large size like industrial buildings. The greenhouse which is miniaturized is called as a cold frame. The modern greenhouses are made up with screening installations, heating, cooling, lighting, computer to provide required favorable conditions for plant growth and it also manages the micro-climate conditions by controlling parameters like air, temperature, relative humidity, and vapor pressure deficit etc.

In greenhouse the interior part is exposed to sunlight so that it becomes significantly warmer than the external temperature suitable for crops to protect it from cold weather condition. This technique enables the farmer to get increased growth and productivity. In which they can control the growing of any crops under partial and fully controllable environmental conditions. These Greenhouse Technologies provides the suitable environmental conditions in which one can grow any plant in any place at any time by controlling suitable conditions in different parameters with minimum labour an enables certain crops to be grown throughout the year, It protects the plants from the adverse climatic conditions such as wind, cold, precipitation, excessive radiation, extreme temperature, insects and diseases.

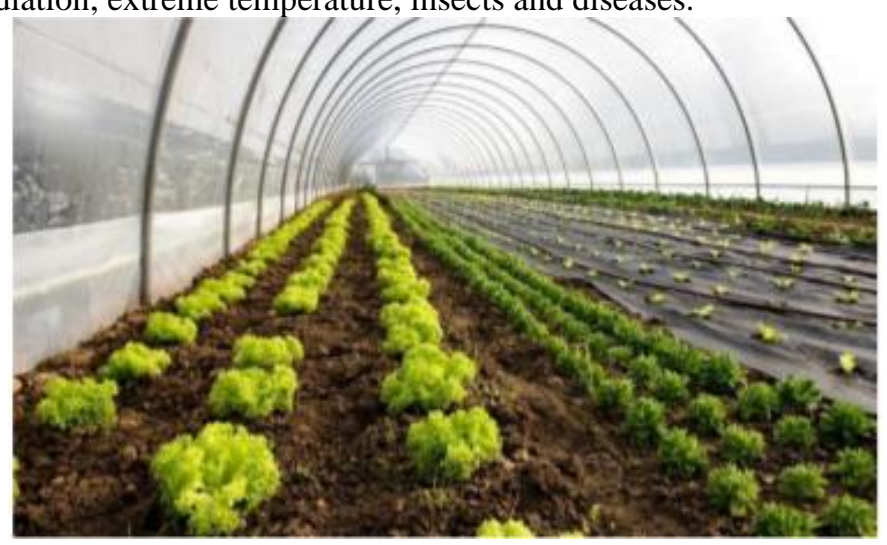

Fig. 1. Greenhouse 
By using modern technologies, we are designing an automated greenhouse which prevents spoilage of crops due to heavy and uneven rainfall. It consists of roof which can close during heavy rainfall and open during the conditions specified by the user. Roof can be controlled automatically and manually. This system can monitor different physical conditions like humidity, moisture and temperature suitable for a growth of plant specified by the user.

Generating power and supply is a difficult task. India has 138 Crore people. Supplying each one is not possible. In India we are generating power through Non-renewable energy like coal, petroleum and renewable energy like solar, wind, water etc. Non-renewable energy cause lot of pollution and there are already becoming less. So, generation of power through renewable energy is very important and this is only way we can control pollution and can generate energy. Renewable energy is purest form of energy. In our project we are making use of solar panels to generate power. In India solar energy is the hoping way and efficient way of power generation. We can generate more power from it. Cost of installation is more but it maintenance cost is less and life time of solar panels are also more.

Power generation technique is also proposed where power is generated by solar energy. Using IOT technology user can control or operating the overall process manually or automatically from anywhere. Rainwater harvesting is also a part of this project where collected rainwater can be used for different agricultural purposes like irrigation and other domestic purposes. Using IOT technology user can control or operating the overall process manually or automatically from anywhere.

\section{Objectives of the proposed work includes,}

- To protect the crops from heavy rain fall and increase the yield.

- Generation of power using solar energy.

- Protect cops using Green house technique.

- To control operations regarding to closing and opening of Roof and other operations manually through IOT technology.

\section{LITERATURE SURVEY}

In some regions the water supply is insufficient, in that regions there is necessity of preserving of the water for agriculture. Conserving of rainwater helps in various agricultural needs. This can be achieved using rainwater harvesting and other advanced irrigation techniques helps in better use of water. The main key to overcome is to establish a various domain of concern such as land, farm, water tank etc. There are some advancements irrigation engineering techniques i.e., drip irrigation, site-specific variable rate irrigation. By using these techniques, the farmer gets benefitted by the reduced water consumption and reduced soil evaporation loses. Initially irrigation project cost is high because of this, taxes to the cultivator is more in the form of levy. The proposed system requires more operating knowledge for farmers. By using sprinkler irrigation method crops can damaged because by changing the sprinkler system many times, also water should be clean while using the sprinkler method. [1]

To monitor temperature, humidity and moisture in the soil of agricultural land done by using IOT. Large number of crops have been destroyed due to difference in weather condition. Sensors collect the field information i.e., more accurate and measure the various parameters like temperature, moisture, humidity content in soil which helps to reduces the problems in agricultural field. The RFID technology is used to track and identify the object, or a crop and it helps in communication by sending or receiving information. The moisture contents in the soil is sensed by using the moisture sensor and it will identify the amount of water supply required to the crop and sends data to RFID and enables the sensor to supply water which automatically turn on the water source and turn off it when need is satisfied. The process of encryption of data stored in RFID systems can be quite expensive. Also, the cost of RFID tags is higher when compared with other alternatives. [2]

The internal parameters of Greenhouse can be controlled by

modifying temperature, humidity, concentration $\mathrm{CO} 2$, micro/macro nutrients. We know that greenhouse is the climatic model has nonlinearity, strong coupling, feedbackfeed forward linearization and decoupling. To overcome from this PSO-PI is used. Firstly, nonlinear multiple inputs multiple outputs MIM0 system. This transferred to SISO to eliminate the temperature and humidity coupling. The major disadvantage is when PI used alone it works poorly. [3]

Automatic control of temperature in green house is done by using a technology called commercial embedded system. The system is designed in such a way that it can provide the appropriate air temperature in the region where the crops are grown. The measured data is given to the algorithm of cascaded PID and it is implemented in embedded system. Manipulates actuators like heating, cooling and fans with respect to the actuators. It is difficult to distribute the fresh air to entire greenhouse. The main disadvantages are lack of water, salinity, higher air temperature and levels of humidity. [4]

The system to monitor agricultural land is developed by using WSN. From the level of production and quality of crops increases. The main advantage of this is no manual interface. The factors on which production, Quality and growing level depends are temperature, humidity and water level. We can also call WSN as WSAN where physical and environmental conditions like temperature, sound, pressure and other are monitored using autonomous sensors which are distributed. To monitor and crop production microcontroller along with sensors are used. Depending upon the threshold value motor is automatically controlled. Through IOT monitored data is sent to cloud.so that farmers can get the data easily. Disadvantages are low response of WSN, less accuracy and cost of the technology is more. [5]

The parameters such as air humidity, temperature, ground moisture and environment lightness can be controlled under greenhouse environment. The data collection of these parameters can be done by using hierarchical WSN technology. The lower level consists sensor nodes, the middle level consists of router nodes. This node transmit data from 
sensor nodes to a coordinator node. The coordinator node (highest level), is used to communicate with a central base, where all data received are analysed in each sensor node and the water pump is controlled in response to the soil sensor node. Sensor values are captured by microprocessor by reading the analog port. These values are converted to a scale from 0 to 9 . A lower value represents dry soil, and a higher value represents wet soil. If the value indicates that the soil is dry, the coordinator node will send a message to the actuator in which it turns on the water pump. The inconsistent use of intermediate nodes can lead to complexity in routes and it causes multiple route request messages in response to a single route request message thus it can lead to heavy control overhead. [6]

To monitor agricultural land conditions, to control water irrigation and to take proper decisions, actions for that is the main agenda of this paper. In this paper WSN is used. WSN contains nodes of sensors where each node can detect physical parameters like light, heat, pressure and other. WSN has networking capability so that monitoring can be done continuously. WSN are very popular and advantageous method of data collection from that communication, efficiency, reliability of the system is improved. WSN is very powerful to collect the data and process the data. The cost and energy consumption of this system is less. [7]

The greenhouse which can monitor real time sensors, control the switches and the data is analysed dynamically and efficiently by using Splunk platform. Hardware of this have two parts sensors/actuators, severs. Raspberry Pi and notebooks are in servers. The information from sensors/actuators is given to web applications to facilitate the users. So that it is easy to control actuators and switches. Disadvantages are Splunk's very expensive, dashboards functional but not as effective as some other monitoring tools. We need to spend lots of time to learn those tools [8]

Management of greenhouse using IOT is done by using sensors networks and technologies based on web. This IOT contains technologies and processors which have capacity of process large data. Hardware devices connections are done by short distance wireless communications technologies like Bluetooth, Wi-Fi and Zigbee. To manage system parameters like temperature, humidity by using remote and to view the greenhouse status, Zigbee is more advantageous to make system more secure we need to adopt higher technologies. The transmission rate of this system is less. If we adopt Zigbee then cost will increase further. If we want to make the system smaller, use less sensors, simplify Zigbee networks, improve area of greenhouse will increase system complexity. [9]

The economy water in underground is increased by irrigation system through smart climate agriculture which concentrate more on climatic changes which affects the security offered. This simple system which can be built by using less cost and that system can monitor soil moisture using sensor and schedule plant irrigation using GSM. We can control and monitor the system using Zigbee also automates the irrigation through simple WSN. No self power generation in this system and power is externally supplied by the battery. [10]
In tropical countries green houses are suffering from controlling the changes in temperature and humidity. This research paper finds a solution for controlling some parameter under greenhouse condition in tropical countries which consists of humidity and temperature. The different inside and outside parameters of greenhouse is monitored in the first step. In accordance with the monitored data system of climate control is designed in the next step. The greenhouse construction is done in such a way that it is flexible for the air flow and ventilation process by measuring the internal conditions inside the polyhouse by using the system which can monitor climate and that system which is outside the green house. The disadvantage regarding to this research is damaged sensors and errors in data processing system can cause problems in decisions which may be led to excess use of water, fertilizers and other dissolution of resources. [11]

Greenhouse with manual systems are monitored by workers every day. Temperature and humidity monitoring causes discomfort to the worker as visit the greenhouse every time and controlling the parameters. The adoption of IOT in greenhouse provide the solution for the existing practical problems. These includes temperature, humidity and moisture contents so these sensors configured to microcontroller to analyses the parameters. The watering of crops is provided with suitable type of irrigation. Once the threshold values of sensors fall below the reference values, the microcontroller decides and take suitable control actions via cloud platform. Thus, enabling the sensors to meet the required threshold values. The disadvantages of system are there is no adaptions of IOT in greenhouse it fails to provide manual control, and real time communication to the farmer. [12]

The growth and development of crops in greenhouse are mainly influenced by the air temperature and climate distribution. The outside and inside parameters like air temperature, radiation of soil and humidity are measured. To predict and simulate the generated energy annually at different angles is done by Polyson program. The BIPV panel is installed at a tilt angel of 30 degree which is placed just to cover south roof part (BIPV panel parameter depends on temperature). Installation of semi-transparent photovoltaic on greenhouse depends on temperature parameter. When solar radiation falls on the semi-transparent photovoltaic it converts solar energy into electrical energy so that power is generated. The disadvantage is power generation is less. [13]

The advancement and installation of IOT in greenhouse leads to smart system automation and control of internal parameter through scientific and efficient manner. This automation of greenhouse adopted is done through stages such as, layer of recognition, network construction, management service and compressive applications. The layer perceptual recognition layer is used to collect various greenhouse environment factors which has direct contact with the sensors installed at different places in greenhouse. The hardware of the system includes greenhouse gateway devices which mainly functions with the reliable communication with cloud services, heating device control, equipment of irrigation, ventilation and high compensation in green house. The sensors nodes mainly function to collect sensed information send to gateway devices. Information from nodes 
of sensors are transmitted through serial port of wireless communication system. These highly intermediate nodes lead to inconsistent data with multiple route access in response to the single route access which leads to heavy control overhead. [14]

The agricultural automation improves irrigation, protects land and manage the health of crops. To improve irrigation, to monitor things, a system to identify and classify affected plants autonomous rover is used. Autonomous rover performs in three levels. First level which is basic consist of motor, encoder, chassis and battery. Second level consist of main board and motor driver for controlling. For autonomous navigation last level has IMU and GPS. Because of less humans to do physical work many people lost their jobs. [15]

Water management system using IOT is designed where Lora communication cannot connect to internet manually as well as automatically. From the sensors embedded in the farm tunnels and other locations system receives real time data. After that capacity check and water scheduling will happens. To that data and time of watering scheduled, system gives notification to the user so that water pump will be switched on to water the Usage of multiple technologies leads to complexity and many other factors affects price. [16]

The automation of the greenhouse system consists of execution of miniature system with a scale of 1:10. The development board is equipped Arduino, humidity, temperature and light intensity measuring sensors. The microcontroller development board Arduino is configured with converters, circuit brakes to drive motors when necessary. The data collected by the sensors such as temperature, humidity sensors are interfaced with serial communication to the computer. Considering all the factors, it is very difficult to analyze and decide if automation system is efficient or not. [17]

The application of excessive pesticide to the plant cause harmful impacts on the environment. The IOT feature of managing crops production in precision agriculture optimizes the quality of crops by applying required nutrients. The application of machine learning algorithm and graphical user interface are deployed with sensing networks to gather the required field data of some crops such as potatoes, cabbage, tomatoes etc. The gathered data from sensing nodes are fed to machine learning algorithm displaying both data and warning message through a graphical user interface. [18]

\section{METHODOLOGY}

\section{A. Basic idea}

The basic idea beyond using IOT in agriculture is to protect the crops during different seasons. As the many techniques are applied in agricultural sector greenhouse technique is also one of them. As of controlling and monitoring of greenhouse using IOT and some other technologies are implemented. By observing all the technologies which are carried out on the greenhouse, so we are designing a greenhouse system which can control the parameters in the greenhouse. There are different structures of greenhouse are present and their specifications is as mentioned in the below TABLE I.

\begin{tabular}{|c|c|c|c|}
\hline Type & $\begin{array}{l}\text { Parameters } \\
\text { controlled }\end{array}$ & Advantages & $\begin{array}{l}\text { Disadvanta } \\
\text { ges }\end{array}$ \\
\hline $\begin{array}{l}\text { Semi closed } \\
\text { greenhouse }\end{array}$ & Heat & $\begin{array}{c}\text { Greater control of } \\
\text { air movement and } \\
\text { humidity }\end{array}$ & $\begin{array}{l}\text { Less } \\
\text { cooling } \\
\text { capacity }\end{array}$ \\
\hline $\begin{array}{l}\text { Conventional } \\
\text { green house }\end{array}$ & $\begin{array}{l}\text { Greenhouse } \\
\text { gases }\end{array}$ & $\begin{array}{l}\text { Suitable for large } \\
\text { scale growers }\end{array}$ & $\begin{array}{c}\text { Initial } \\
\text { building } \\
\text { cost is high }\end{array}$ \\
\hline $\begin{array}{l}\text { Partly closed } \\
\text { greenhouse }\end{array}$ & $\begin{array}{l}\text { Green house } \\
\text { gases }\end{array}$ & $\begin{array}{l}\text { Provide natural } \\
\text { growing of plants }\end{array}$ & $\begin{array}{c}\text { High } \\
\text { humidity } \\
\text { cause plant } \\
\text { diseases }\end{array}$ \\
\hline $\begin{array}{l}\text { Ideal closed } \\
\text { greenhouse }\end{array}$ & $\begin{array}{l}\text { Greenhouse } \\
\text { gases }\end{array}$ & $\begin{array}{c}\text { Greater control of } \\
\text { diseases }\end{array}$ & High cost \\
\hline $\begin{array}{l}\text { Open roof } \\
\text { greenhouse }\end{array}$ & $\begin{array}{l}\text { Tempreture,Hu } \\
\text { midity,Rain. }\end{array}$ & $\begin{array}{l}\text { Opening maximizes } \\
\text { light and } \\
\text { ventilation, diseases } \\
\text { control, provides } \\
\text { ideal growing } \\
\text { conditions, } \\
\text { protection from rain }\end{array}$ & $\begin{array}{l}\text { High initial } \\
\text { cost }\end{array}$ \\
\hline
\end{tabular}

\section{B. Basic syatem flow}

The propose system is designed by incorporating various hardware and software technologies in to it. The proposed system uses ARM7 LPC2148 microcontroller as a main control unit and all the controlling operations and executions have been carried out by this microcontroller. This system uses multiple sensors to monitor and control various parameters like temperature, moisture content in the soil, humidity etc. The sensors include humidity sensor, IR sensor, moisture sensor and rain sensor/rain switch as shown in the Fig. 2. This sensor provides various readings that will help monitor and control the greenhouse. Entire system works in both automatic mode as well as in manual mode. By using IOT technology proposed system also enables the manual monitoring of green house from anywhere. Power is generated as part of this system using solar panels placed on the roof top of the greenhouse.

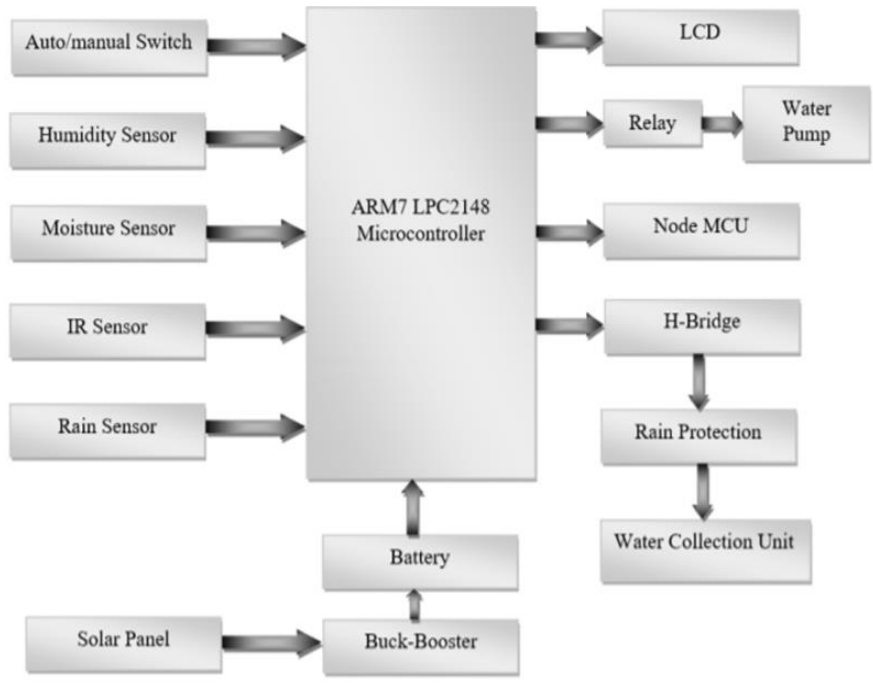

Fig. 2. Block diagram of the proposed system 


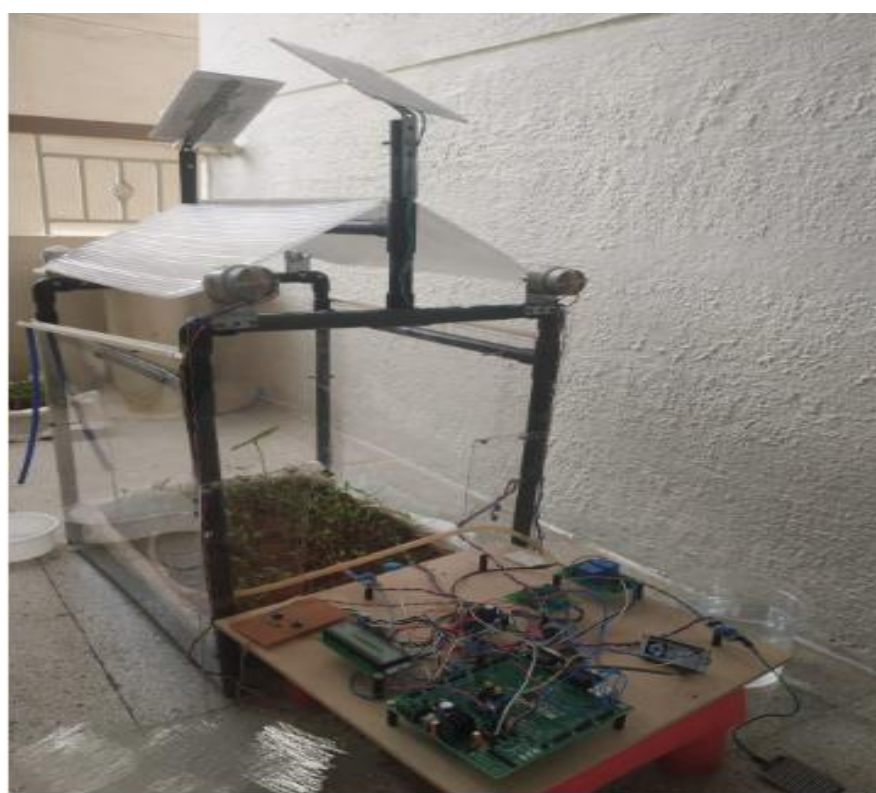

Fig. 3. Image of actual implemented model.

\section{System algorithm}

As the greenhouse structure is used to protect the crops.

The basic process of system is as follows:

- The system works in either automatic mode or manual mode. It is set before the system starts the operation.

- Sensors that are present in the greenhouse measures the parameters like moisture in the soli, temperature, humidity and presence of rain etc. Then sends these measured values to the microcontroller.

- Microcontroller checks for the threshold conditions. If the measured value reaches this threshold value, then it takes controlling operations. For example, if moisture content in the soil is reaches the threshold value for the crop then it automatically turns off the water pump or if it is below threshold level it turns on pump.

- To protect the crops during rainy season the rain sensor will sends the signal to microcontroller about the presence of rain then the roof top of the greenhouse will be actuated by the motor according to the measured value of the sensor.

- Power generation is also part the system using solar panels on the roof top of the greenhouse is store the solar power. This solar power is boosted to the voltage so that the system will work with this voltage or it will used for other purposes.

- Rainwater is collected during rainy season. That water is used for irrigation purposes.

This System works in two modes i.e, automatic mode, manual mode. Fig. 3, Shows the image of actual implemented model.

In the automatic mode of controlling and monitoring of the system, the sensors which are in the agricultural land senses the respective parameters like temperature, soil moisture content, presence of rain and sensing any obstacle around the greenhouse. Then any one of the parameters reaches its threshold level it automatically sends signal to the microcontroller. Accordingly, it reads the signal and take necessary actions like controlling and actuating etc. The sequence of operations which are carried out in automatic mode as shown in the Fig. 4,Flow .

To enable the system working in the manual mode we are using IOT technology like telegram bot. In this mode all the controlling and monitoring of greenhouse is carried out through internet. Communication is takes place between farmer and greenhouse. By receiving the monitored values of the parameters the farmer can control the greenhouse anywhere and in anytime. The sequence of operations which are carried out in manual mode as same as automatic mode but instead the system automatically takes process to happen here the farmer will control the whole operation which is far from the land through instant messaging through telegram app using internet services.

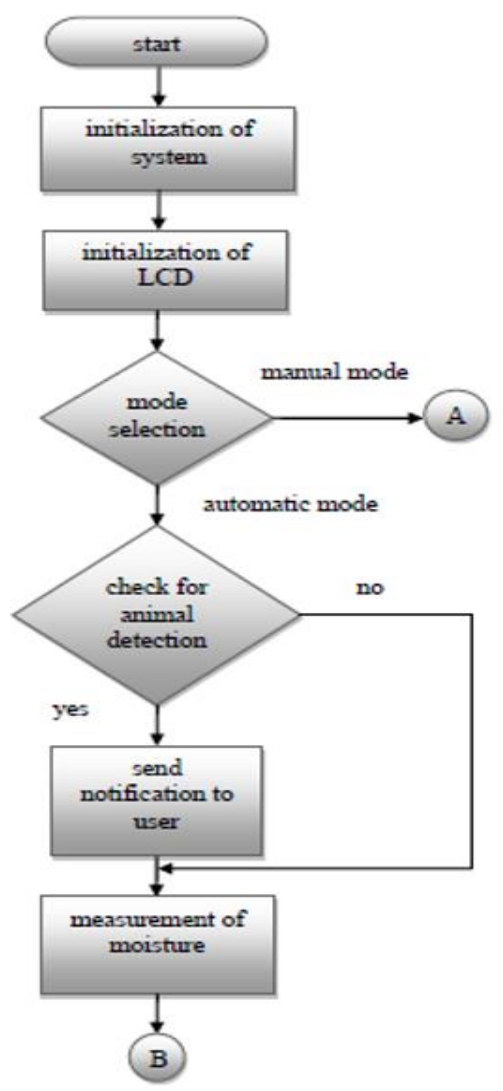




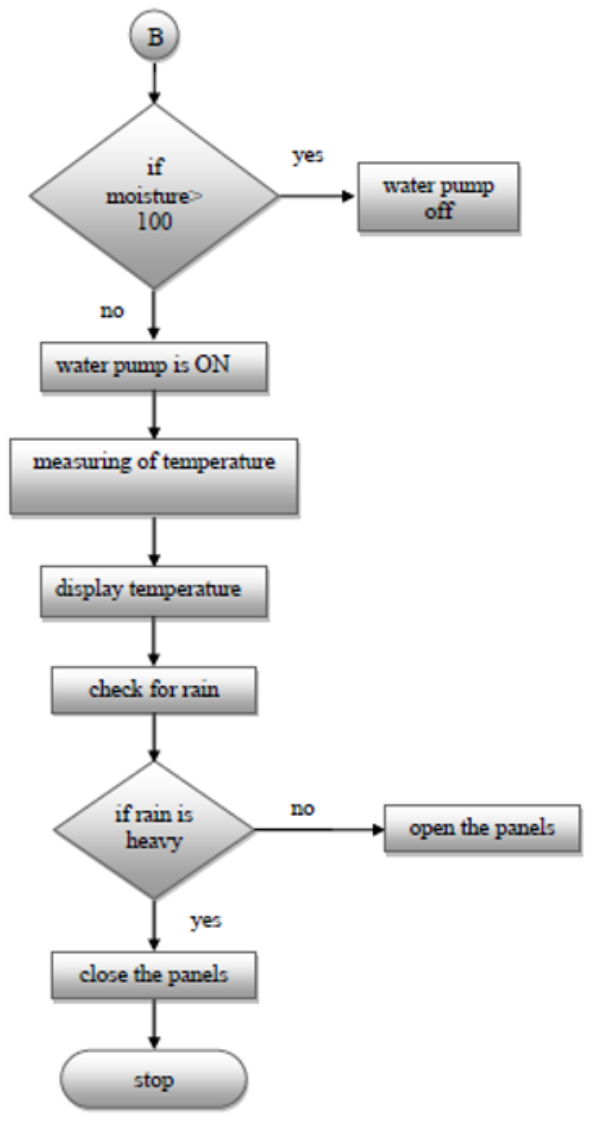

Fig. 4. Flow chart for automatic mode of control.

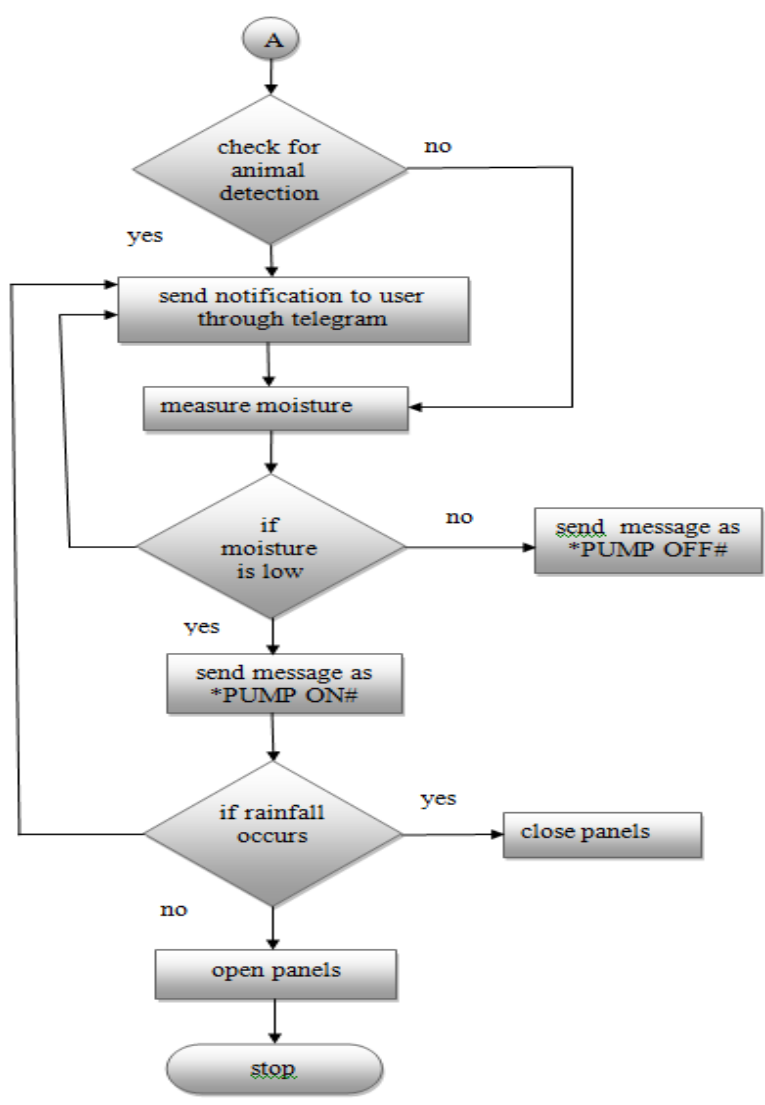

Fig. 5. Flow chart for manual mode of control.
In this proposed system automatic mode and manual mode of monitoring and controlling operations of the green house are the primary activities and secondary activities which is performed in the green house for cultivating the plants is shown in TABLE II.

TABLE II. SECONDARY ACTIVITIES

\begin{tabular}{|c|c|c|c|}
\hline Type & Daily & Weekly & Monthly \\
\hline Irrigation & & & \\
\hline Pets/disesses & & & \\
\hline Weeds & & & \\
\hline ventilisation & & & \\
\hline fertilization & & & \\
\hline Tempreture and Humidity & & & \\
\hline
\end{tabular}

IV. RESULT AND DISCUSSION

We will build a small greenhouse which is the area of $67 X 49$ in centimeter. Here we used polycarbonate sheets made of rigid plastic that transmits light almost like glass sheet. Here we are concentrated on growing one crop in the greenhouse which is green chilly named as Serrano pepper grouped under commercial crop. It requires a $24^{\circ} \mathrm{C}-27^{\circ} \mathrm{C}$ temperature. So that temperature is maintained by setting this value. Crop needs well drained sandy loam soil with rich organic content. It requires a moisture in the soil. In order to keeps the soil in moisture condition here it is set to 100 . If the moisture content goes beyond 100 then it will automatically shut down the water pump through relay if it is working in automatic mode otherwise send the notification to the farmer shutdown the water pump.

Our main objective is to protect and growing the crops during rainy season as many farmers will not get high yield during these days due to heavy rainfall. Rain sensor will notify the presence of rain comes. If it is heavy rain, then the roof top of the greenhouse will automatically be closed and protect the crops and completely shutdowns the irrigation process. That rainwater is collected, and it is used for other purposes also.

When the power is switched on the system gets initialized and it is the first step. The message will be displayed on the LCD screen. Fig. 5, shows the initialization of the system

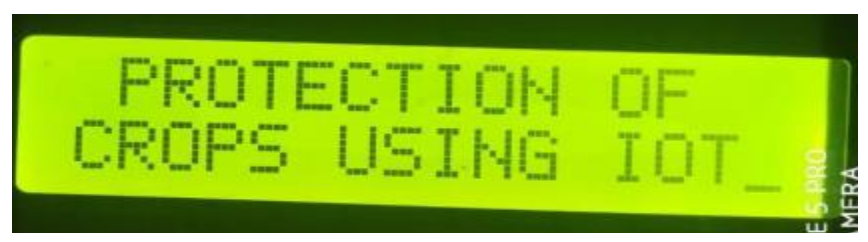

Fig. 5. System initialization. 
As soon as the system is initialized, it asks for the user to select either auto mode or manual mode. The user will be provided by two switches may select the option depending on his requirement. Fig. 6 . shows the mode selection.

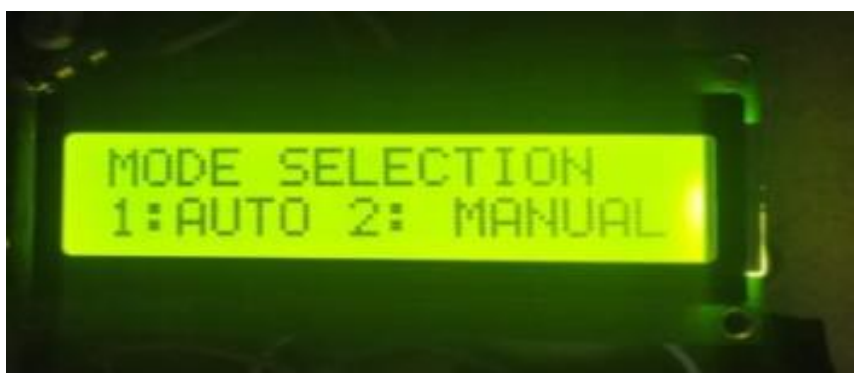

Fig. 6. Mode selection.

Moisture sensor measures the moisture level in the soil.If the moisture level is normal then that indicates there is sufficent amount of water is present in the soil, if the moisture level is below the normal value it indicates that the land is dry, in that case the user need to turn on the motor to water the field. Fig. 7. shows the measuring of moisture level in the soil.

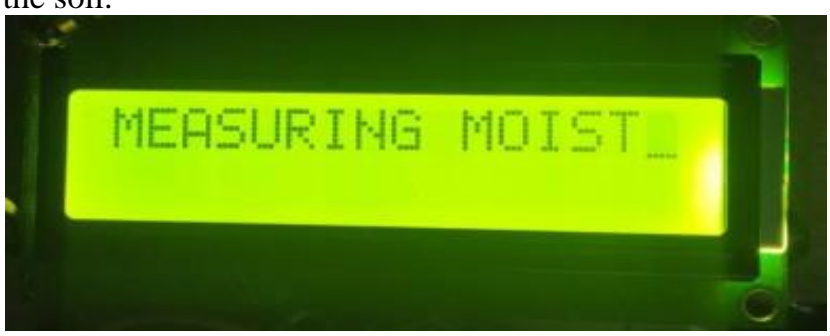

Fig. 7.moisture measurement

Humidity sensor measures the moisture content in the air and display the value of the humidity and it also measures the temperature of the environment and display the value in LCD screen. Fig. 8.and Fig .9. shows the measurement of humidity and temperature..

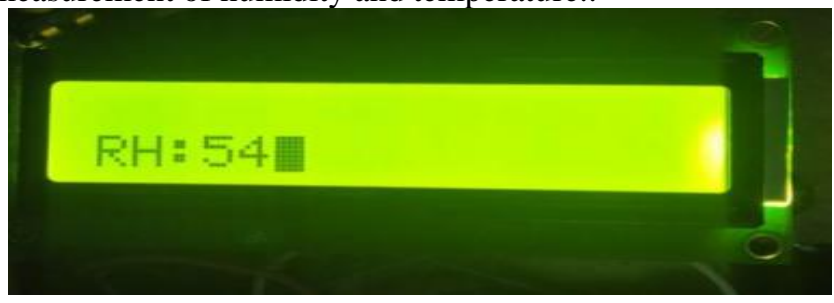

Fig. 8. measurement of humidity.

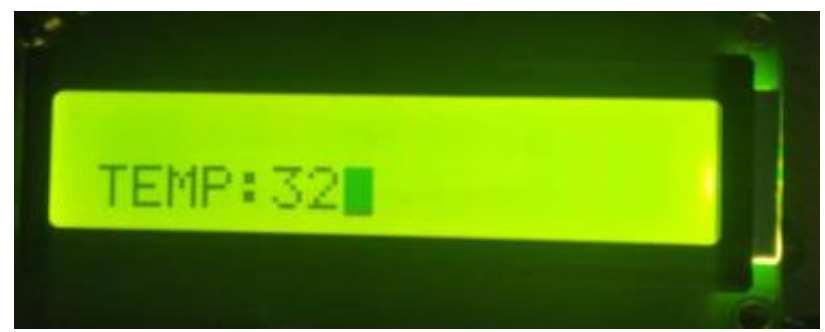

Fig. 9. measurement of temperature.

If the rain sensor detects rain then the panels will get close to protect the crops from rain otherwise the panels will remain open. Fig. 10. shows the opening of the roof panels when its not raining and figure. 11. Shows the closing of panels when there is a rain to protect the crop from the rain. And corresponding message is displayed on the screen regarding to opening and closing of the panels and also corresponding message is also sent to the farmer in manual mode through telegram app.

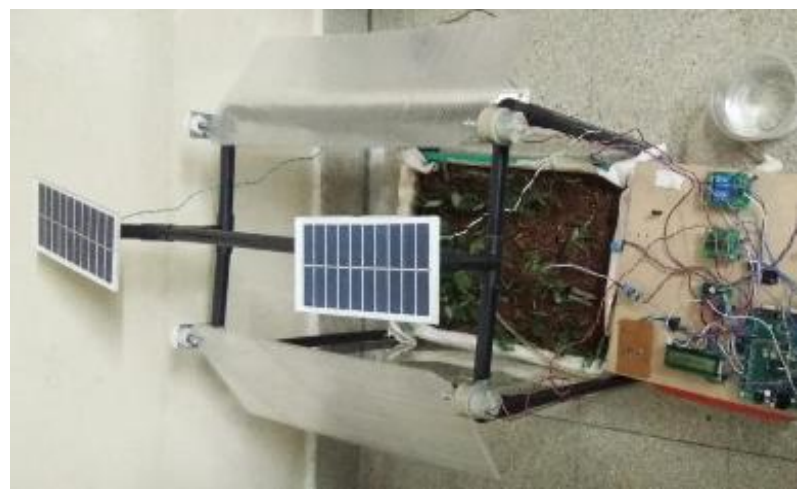

Fig. 10. Opening of panels.

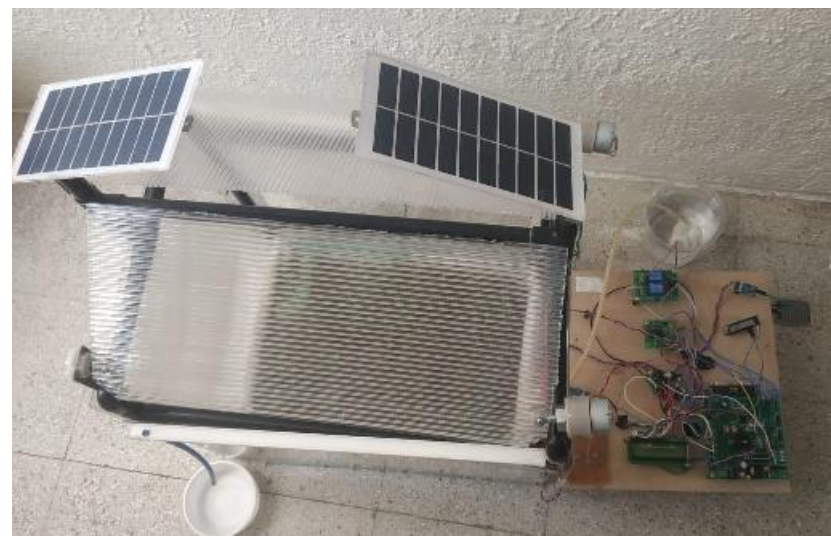

Fig. 11. closing of panels.

In manual mode of controlling the green house the farmer can monitor and control the operations of the green hose through telegram app. All the messages regarding to moisture content in the soil, opening and closing of panels sent to the farmer. Farmer also control the on and off the water pump by giving the commands as *PUMP ON\# for on the water pump and *PUMP OFF\# for off the water pump according to the received messages regarding to the moisture content in the soil. Fig. 11.shows the monitoring and controlling of the green house through telegram app. 


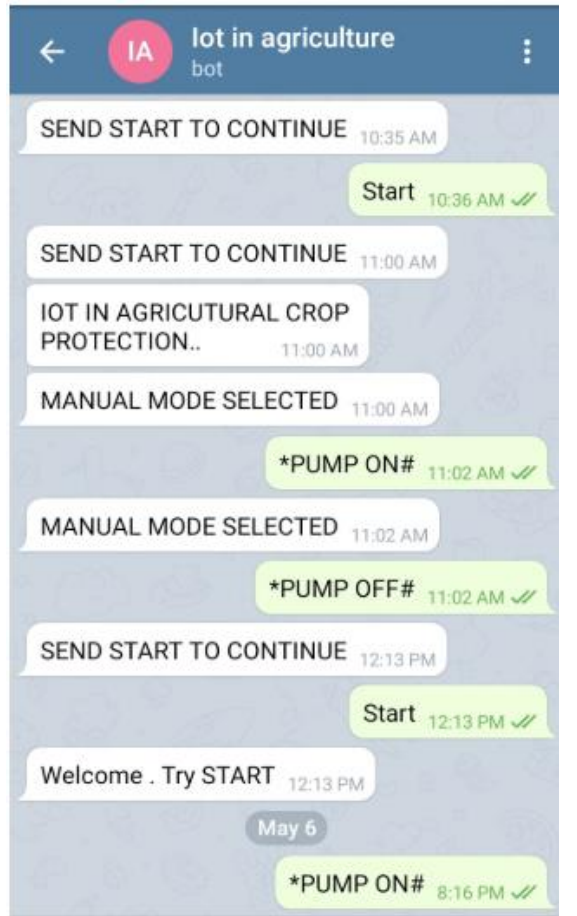

Fig. 12. Telegram app messaging screen.

We compared yield from the crop that are grown inside the greenhouse and with normally grown crop. The yield and the along with the power generated from solar panels if it is built in acre, hectare are shown in Table-II

Table-III: Comparison of the yield and generated power

\begin{tabular}{|c|c|c|c|c|}
\hline Area & Crop & Power generated & $\begin{array}{c}\text { Yield by old } \\
\text { method }\end{array}$ & $\begin{array}{c}\text { Yield by } \\
\text { proposed } \\
\text { method }\end{array}$ \\
\hline $67 \mathrm{X} 49 \mathrm{~cm}$ & $\begin{array}{c}\text { Serrano } \\
\text { pepper }\end{array}$ & $\mathbf{5 - 6 W}$ & $\mathbf{5 0 g}$ & $\mathbf{7 5 g}$ \\
\hline $\begin{array}{c}\text { Per half } \\
\text { acre }\end{array}$ & $\begin{array}{c}\text { Serrano } \\
\text { pepper }\end{array}$ & $\mathbf{1 5 0}$ to $250 \mathrm{~W}$ & $\mathbf{5 - 6 k g}$ & $\mathbf{7 - 8 k \boldsymbol { g }}$ \\
\hline Per acre & $\begin{array}{c}\text { Serrano } \\
\text { pepper }\end{array}$ & $\mathbf{1 K \boldsymbol { w }}$ & $\mathbf{1 5 0 k g}$ & $\mathbf{1 9 8 k g}$ \\
\hline $\begin{array}{c}\text { Per hectare } \\
(2.5)\end{array}$ & $\begin{array}{c}\text { Serrano } \\
\text { pepper }\end{array}$ & $1 \mathrm{MW}$ & $375 \mathrm{~kg}$ & $429 \mathrm{~kg}$ \\
\hline
\end{tabular}

The solar panels which are placed on the roof top of the green house results in significant generation of power. Voltage generated by these solar panels is stored in the battery and is used to control the operations in green house. The voltage generated during summer season and variations in voltage generation on the different times in a day is observed. According to the collected readings graph is plotted for voltage generated during time and temperature. In Fig. 4Fig.8 shows the graphs for generation of voltage with respect to time and temperature up to 5 days is plotted.

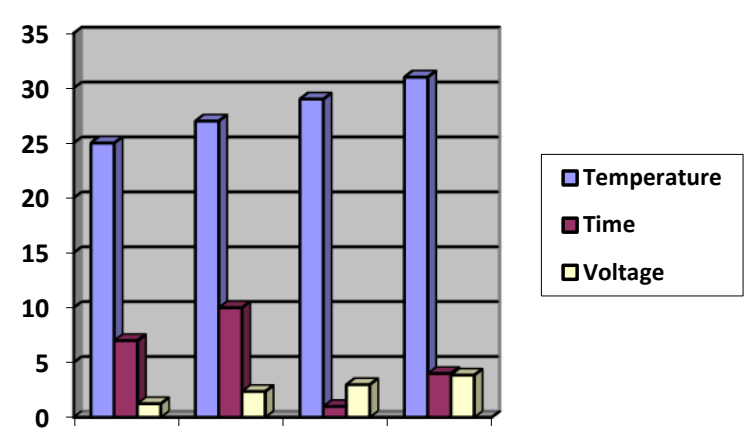

Fig. 13. Analysis of day 1 solar power generation.

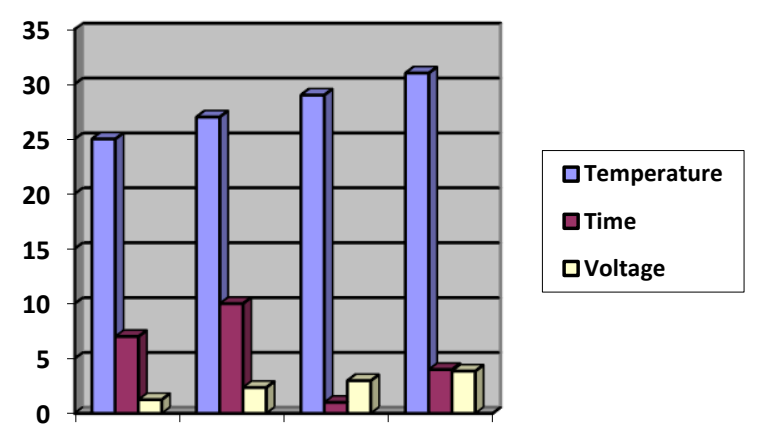

Fig. 14. Analysis of day 2 solar power generation.

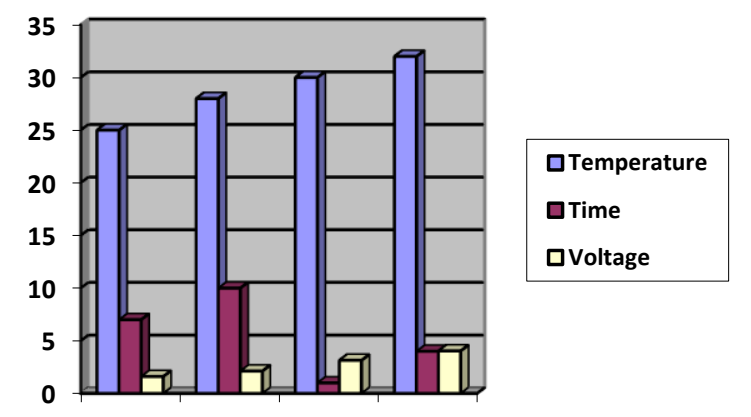

Fig. 15. Analysis of day 3 solar power generation.

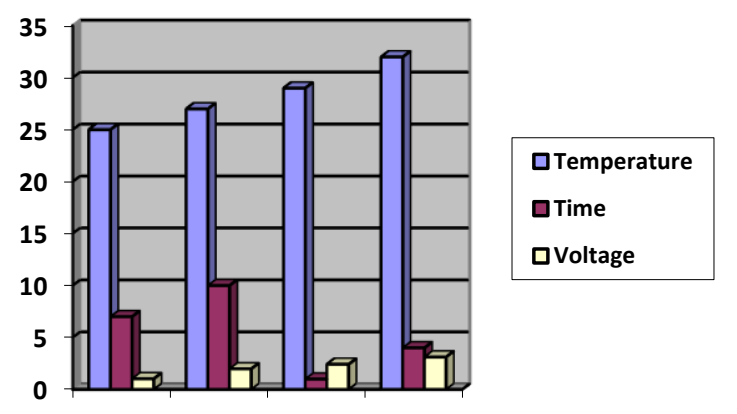

Fig. 16. Analysis of day 4 solar power generation. 


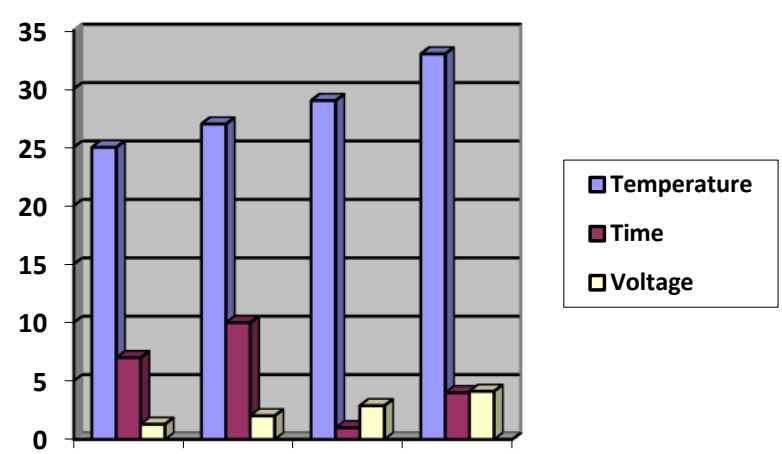

Fig. 17. Analysis of day 5 solar power generation.

\section{CONCLUSION}

As our main intention to protect the crops and along with the generation of power using solar panel is established and the parameters to grow the crop according the suitable environment is created using greenhouse structure. Actuating roof of the greenhouse helps to protect the crop in any climatic conditions. Using IOT technology it helps the farmers to control their filed anywhere is simple and now it is cost effective. This system helps to solve power supply problem and this helps in yielding.

\section{REFERENCES}

[1] Mateos, L., \& Araus, J. L. (2016). Hydrological, engineering agronomical, breeding and physiological pathways for the effective and efficient use of water in agriculture. Agricultural Water Management, 164, 190-196. doi:10.1016/j.agwat.2015.10.017

[2] Wasson, T., Choudhury, T., Sharma, S., \& Kumar, P. (2017). Integration of RFID and sensor in agriculture using IOT. 2017 Internationl Conference on Smart Technologies for SmartNation (SmartTechCon). doi:10.1109/smarttechcon.2017.835837 2

[3] Gouadria, F., Sbita, L., \& Sigrimis, N. (2017). A greenhouse system control based on a PSO tuned PI regulator. 2017 International Conference on Green Energy Conversion Systems (GECS). doi:10.1109/gecs.2017.8066235

[4] Alsharakhat, A., Almoalem, M., AlHawaj, N., Papageorgiou, C., Sadriwala, A. (2017). Temperature Control of a Greenhouse System Using Embedded Systems Technology. 2017 9th IEEE-GCC Conference and Exhibition (GCCCE). doi:10.1109/ieeegcc.2017.8447937

[5] Infantian Rubala,D. Anitha., "Agriculture Field Monitoring using Wireless Sensor Networks to Improving Crop Production” 2017 IEEE International(2017).

[6] Sampaio, H., \& Motoyama, S. (2017). Implementation of a greenhouse monitoring system using hierarchical wireless sensor network. 2017 IEEE 9th Latin-American Conference on Communications (LATINCOM). doi:10.1109/latincom.2017.8240156

[7] Wireless Sensor Network and Monitoring of Crop Field Joshi P P1 Dr.Kanade S S2 , Dr.Joshi S P3 e-ISSN: 2278- 2834,p- ISSN: 22788735. Volume 12, Issue 1, Ver. II (Jan.-Feb. 2017), PP 23-28

[8] Chen, Y.-J., \& Chien, H.-Y. (2017). IoT-based greenhouse system with splunk data analysis. 2017 IEEE 8th International Conference on Awareness 1Science and Technology (iCAST). doi:10.1109/icawst.2017.8256458

[9] Li, Z., Wang, J., Higgs, R., Zhou, L., \& Yuan, W. (2017). Design of an Intelligent Management System for Agricultural Greenhouses Based on the Internet of Things. 22017 IEEE International Conference on Computational Science and Engineering (CSE) and IEEE International Conference on Embedded and Ubiquitous Computing (EUC). doi:10.1109/cse-euc.2017.212

[10] Applying Internet of Things in Monitoring and Control of an Irrigation System for Sustainable Agriculture for Small-Scale Farmers in Rural
Communities Ray Mulenga,Josephat Kalezhi, Sonile K. Musonda, Suzyo Silavwe

[11] Low Cost and IoT based Greenhouse with Climate Monitoring and Controlling System for Tropical Countries Yasas Pansilu Jayasuriya, Chanuka Sandaru Elvitigala, Kolitha Warnakulasooriya, BH Sudantha IEEE member

[12] University of Moratuwa, Faculty of Information Technology, Moratuwa, Sri Lanka Hassanien, R. H. E., Li, M., \& Yin, F. (2018). The integration of semi-transparent photovoltaics on greenhouse roof for energy and plant production. Renewable Energy, 121, 377-388. doi:10.1016/j.renene.2018.01.044

[13] Danita, M., Mathew, B., Shereen, N., Sharon, N., \& Paul,J. J. (2018). IoT Based Automated Greenhouse Monitoring System. 2018 Second International Conference on Intelligent Computing and Contro Systems (ICICCS).doi:10.1109/iccons.2018.8662911

[14] Changqing, C., Hui, L., \& Wenjun, H. (2018). Internet of AgricultureBased Low Cost Smart Greenhouse Remote Monitor System. 2018 Chinese Automation Congress (CAC). doi:10.1109/cac.2018.8623230

[15] S, G., M, D. D., K, D., \& R, H. P. (2019). Smart Irrigation with Field Protection and Crop Health Monitoring system using Autonomous Rover. . 2019 5th International Conference on Advanced Computing \& Communication Systems (ICACCS). doi:10.1109/icaccs.2019.8728468

[16] Khoa, T. A., Man, M. M., Nguyen, T.-Y., Nguyen, V., \& Nam, N. H. (2019). Smart Agriculture Using IoT Multi- Sensors: A Novel Watering Management System. Journal of Sensor and Actuator Networks 8(3),45.doi:10.3390/jsan8030045

[17] Cosman, S. I., Moldovan, C. A., Iusan, R. A., Oprea, C., \& Martis, C. S. (2019). Development of an automated system to optimize greenhouse resource consumption. 2019 8th International Conference on Modern Power Systems (MPS). doi:10.1109/mps.2019.8759727

[18] Araby, A. A., Abd Elhameed, M. M., Magdy, N. M., Said,L. A. Abdelaal, N., Abd Allah, Y. T., Mostafa, H. (2019). Smart IoT Monitoring System for Agriculture with Predictive Analysis. 2019 8th International Conference on Modern Circuits and Systems Technologies (MOCAST). doi:10.1109/mocast.2019.8741794 